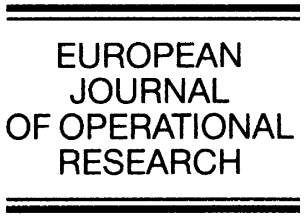

www.elsevier.com/locate/ejor

\title{
Evaluating IT/IS investments: A fuzzy multi-criteria decision model approach
}

\author{
Tzy-Yuan Chou ${ }^{\text {a,1 }}$, Seng-cho T. Chou ${ }^{\mathrm{a}, *}$, Gwo-Hshiung Tzeng ${ }^{\text {b,c,2 }}$ \\ a Department of Information Management, National Taiwan University, No. 1, Sec. 4, Roosevelt Road, Taipei 106, Taiwan \\ ${ }^{\mathrm{b}}$ Institute of Management of Technology, National Chiao Tung University, 1001, Ta-Hsueh Rd., Hsinchu 300, Taiwan \\ ${ }^{\mathrm{c}}$ Department of Business Administration, Kainan University, No. 1, Kainan Road, Luchu, Toayuan County 338, Taiwan
}

Available online 10 August 2005

\begin{abstract}
IT/IS represents a substantial financial investment for many organizations. Whether or not to invest in new IT/IS is, therefore, a difficult decision. Simply considering human resource cost saving criteria is not enough, especially when a corporation has had many information systems. What kind of criteria should we consider when we evaluate IT/IS? How can a new IT/IS project be evaluated in an easy, cost-effective, and collective manner? We need a tool that will help decision-makers evaluate potential new investment projects. Apart from evaluating the new project per se, its compatibility and ability to integrate with an existing IT portfolio must also be considered. Hence, we propose a new approach based on the fuzzy multi-criteria decision model (FMCDM), featuring a 2-stage evaluation process with 26 criteria for IT/IS investment. All stakeholders in a corporation can decide the relative weights they give to the criteria when they evaluate a new IT/IS project by using linguistic values. Experts can also use linguistic values to evaluate all candidates easily. Only an Excel worksheet is needed to obtain an evaluation result. It is cost-effective and efficient. We conduct a case study to show how this model can be used and discuss the results.
\end{abstract}

(C) 2005 Elsevier B.V. All rights reserved.

Keywords: Fuzzy theory; IS evaluation; IT evaluation; IT portfolio; Multi-criteria decision making

\footnotetext{
${ }^{*}$ Corresponding author. Tel.: +8862 33661182; fax: +886223636073.

E-mail addresses: jychou@fdc.gov.tw (T.-Y. Chou), chou@ntu.edu.tw (S.-c.T. Chou), ghtzeng@cc.nctu.edu.tw (G.-H. Tzeng).

${ }^{1}$ Tel.: +88622763 1833x4372; fax: +886227619217.

2 Tel.: $+88635712121 \times 57505$; fax: +88635753926 .
} 


\section{Introduction}

Evaluating or justifying investment in IT/IS (information technology/information systems) is problematic (Ballantine et al., 1998; Powell, 1992; Irani, 2002). Only 16\% of the companies in Hochstrasser and Griffiths (1991) used rigorous methods to evaluate the benefits of IT/IS investments.

However, evaluation is important for three reasons: (1) High cost: IT/IS represents substantial financial investment for many organizations (Willcocks, 1992). Computer and telecommunications investments amount to at least half of most large organizations' annual capital expenditure (Willcocks and Lester, 1997; Premkumar and Ramamurthy, 1995). The World Information Technology Services Alliance in 2000 also reported that the global information and communications industry surpassed the US\$2 trillion mark in 2000 (Irani and Love, 2002). Even governments spend vast amounts of money on IT/IS. The US President's FY 2003 budget requested US\$52 billion for investments in Federal Agency information technology professionals, initiatives, and office operations (Stouffer and Rachlin, 2002). (2) Uncertainty of return: Strassmann (1997) suggested that IT/IS investment produces negligible benefits and there is no linear relationship between IT/IS expenditure and business success (Earl, 1989). Willcocks (1992) suggested that 30$40 \%$ of projects do not realize any net business benefits and that at least $20 \%$ of IT/IS expenditure is wasted. Hochstrasser and Griffiths (1991) also showed that over 25\% of the managers in the organizations they studied did not know if IT/IS investments were better or worse than non-IT/IS investments. (3) A control and management mechanism: Evaluation can provide basic feedback to managers and can form a fundamental component of the organizational learning process. This can be seen as essential for problem diagnosis, planning, reduction of uncertainty, comparing projects, ranking projects in terms of organizational priorities, and as a control mechanism (Smithson and Hirschheim, 1998; Irani and Love, 2002).

Although there are uncertainties of return and vast amounts of money are required, we cannot afford not to invest (Escobar-Perez, 1998) because information systems (IS) can improve organizational efficiency and effectiveness, and provide competitive advantages (Irani, 2002; Powell, 1992). They also offer new ways to manage and organize companies and develop new business (Powell, 1992).

Hence, many kinds of evaluation methods have emerged. Many researchers have made comprehensive and useful reviews of the IS methodologies and approaches that have appeared in recent years (e.g. Powell, 1992; Farbey et al., 1993; Renkema and Berghout, 1997).

However there is increasing debate about the ability of traditional appraisal techniques to measure the 'softer' benefits of IT/IS due to the difficulty in quantifying those 'softer' elements in financial terms for decision-makers (Farbey et al., 1993; Lefley and Sarkis, 1997; Irani, 2002), and to the inability to identify 'hidden' or seldom-considered costs and benefits (Ryan and Harrison, 2000) and organizational problems (Voss, 1986; Irani, 2002).

In addition, traditional appraisal techniques treat the evaluation process in isolation from its human and organizational components and place excessive emphasis on the technological and accounting/financial aspects (Serafeimidis and Smithson, 2003). They do not consider the influence of social, political, or behavioral factors.

The evaluation of IS is moving away from a positivistic approach towards a more interpretive approach among theoreticians (Serafeimidis and Smithson, 2000) and exploring more concerns about social and organizational issues. For example, Mcaulay et al. (2002) focused on discussing attitudes towards the benefits and risks of outsourcing, as expressed by different classes of stakeholders. Meanwhile, Serafeimidis and Smithson (2000) suggested that ignoring organizational changes results in a failure to introduce new entrepreneurial evaluation procedures, and Smithson and Hirschheim (1998) highlighted the organizational and political issues that make evaluation difficult. Serafeimidis and Smithson (2003) investigated the organizational roles of the key stakeholders within the particular evaluation context and provide four evaluation orientations: control, sense-making, learning and exploratory to manage the linkage between IS evaluation and organizational change (including political power). Ryan and Harrison (2000) identified a major source 
of hidden costs and benefits in social subsystem when introducing new IT/IS. Mirani and Lederer (1998) developed an instrument for assessing the organizational benefits of IS projects. Irani et al. (1998) also identified a list of sources of indirect costs, including indirect human costs and indirect organization costs.

The above studies highlight the importance of considering social and organizational criteria in the evaluation process and explain why they are important and what social and organizational criteria should be considered. However, their techniques and constructs have yet to be widely adopted by practitioners (Smithson and Hirschheim, 1998). This may be because there are too many different guidelines that confuse decision-makers, and they are not incorporated into one model for consideration.

Farbey et al. (1993) claimed that the search for a single appraisal technique that addresses all project considerations is very difficult, while Irani and Love (2002) asserted that the development of an all-embracing generic appraisal technique that takes account of the wide variety of IT/IS-related implications may be too rigid and complex for decision-makers to use.

However, it is necessary to provide the manager with an easy to use evaluation tool because, as Hochstrasser argues, the high rate of IT/IS failure is partly attributable to a lack of solid — but easy to use - management tools for evaluating, prioritizing, monitoring, and controlling IT/IS investments (Irani, 2002). Irani (2002) also noted that: "It is expected that a robust evaluation model will help reduce the time needed to make IT investment decisions".

Hence, we propose a model with the following features:

1. Incorporates the opinions of every level of stakeholders in the evaluation process.

2. Integrates the criteria of organization, risk, benefit, and cost into one model.

3. Has the flexibility to allow stakeholders to change the weight of criteria depending on the specific characteristics of the new IT/IS.

4. Is suitable for every organization and sensitive to its culture, because the relative weights of the criteria are determined by the stakeholders.

5. Combines quantitative and qualitative decision-making criteria into one model.

6. Is easy and saves time.

The remainder of this paper is organized as follows. Section 2 presents a review of the literature on IT/IS evaluation criteria, stakeholders, and limitations of AHP (analytical hierarchy process) method. Our proposed approach is then detailed in Section 3. The use of the proposed method is further illustrated with a case study in Section 4. Finally, in Section 5, we present our conclusions.

\section{Literature review}

In this section, we review the IT/IS evaluation criteria, describe the evaluation stakeholders, and discuss the limitations of traditional AHP.

\subsection{IT/IS evaluation criteria}

The criteria for evaluating IT/IS investments are important because they obviously influence the selection result. Many researches have investigated IT/IS evaluation criteria. Bacon (1992) and Escobar-Perez (1998) used the same 15 criteria to investigate the usage of evaluation criteria in American, British, Australian, New Zealand and Spanish firms.

In the evaluation of electronic data interchange (EDI) adoption and integration, Jones and Beatty (1998) summarized prior studies' measures to identify 16 criteria to evaluate EDI systems and use LISREL (LInear Structural RELations) models to find out a better evaluation set with 13 criteria. 
Irani (2002) used a manufacturing company as a case study to classify the MRPII (Manufacturing Resource Planning II) system's benefits as strategic, tactical, and operational benefits. The criteria are financial, non-financial, and/or intangible. Irani et al. (1998) also proposed direct costs and some indirect costs, including two taxonomies: indirect human costs and indirect organizational costs.

Mirani and Lederer (1998) used three LISREL models to determine the generic criteria for measuring the organizational benefits of IS. The criteria include improving competitive advantage, alignment, customer relations, information access, information quality, information flexibility, communication efficiency, system development efficiency and business efficiency.

Information systems are socio-technical entities inseparable from the organizational context within which they are situated and interact, as well as being products of history and human agency (Boland and Hirschheim, 1987; Orlikowski, 1992; Walsham, 1993). Serafeimidis and Smithson (2000) thought that the 'organizational change' criteria should be considered; otherwise, the project failure rate would increase. Ryan and Harrison (2000) also identified 11 social subsystem cost and benefit criteria that should be considered and emphasized their importance. Appendix A presents a summary of the criteria suggested in the above studies.

We condensed Appendix A into a set of 31 criteria. In order to understand whether, or not, an organization's experience with IT/IS and its Chief Executive Officer's (CEO) preferences influence IT/IS evaluation, we added five new criteria to consider. They are: Whether the CEO has IT knowledge, Whether the CEO encourages innovation, Experience in using IS, Failure experience with IS and Maturity of IT. The final worksheet is shown in Table 1.

\subsection{IT/IS evaluation stakeholders}

For the evaluation process and result to be successful, it is not only important to understand the criteria, but the stakeholders who do the evaluation must also be considered because different constituencies have different perspectives, all of which may be equally important (Mirani and Lederer, 1998). For instance, users, IS professionals and managers may differ about the nature of benefits and costs associated with an IS development project. Also, a project's impact may differ according to which group stakeholders belong to (Mcaulay et al., 2002). When different stakeholder groups hold conflicting views, evaluation may become a highly political activity (Walsham, 1993; Smithson and Hirschheim, 1998). It is not surprising, therefore, that Irani (2002) identified "stakeholders' definitions, analyses, and involvement" as important concerns during the IT/IS evaluation process. Therefore, the evaluation team should comprise different stakeholders who will be impacted by the IT/IS.

Mcaulay et al. (2002) classified the stakeholders into three groups: IS management stakeholders, non-IS management stakeholders, and IS-transitioned employee stakeholders. Irani (2002) classified stakeholders into three groups: strategic stakeholders, operational stakeholders, and financial justification stakeholders. In order to collect the opinions of all stakeholders in the organization, we included IS management stakeholders, non-IS management stakeholders, strategic stakeholders, and financial justification stakeholders in our weighting team.

\subsection{Limitations of $A H P$}

Multi-criteria methods are used in many decision-making situations, and are well known for their ability to combine quantitative and qualitative decision-making criteria (Renkema, 2000). Several authors have used the AHP, proposed by Saaty (1980), to evaluate alternate technologies. The method combines all criteria in one model and allows the evaluating company to decide the weight of each criterion. Therefore, the AHP method can be used to evaluate the relative importance weight of criteria/alternative IT projects.

However, the application of traditional AHP to evaluate alternative IT/IS projects has some limitations (Prabhu and Vizayakumar, 2001). These include: 
Table 1

Criteria worksheet

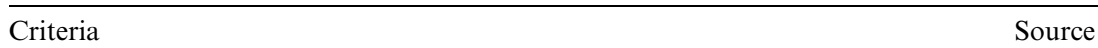

1. Ally with partner (Improved trading partner relations)

2. Government requirement

3. React to competition

4. Organization learning

5. Technical/system requirements (User's requirement)

6. Whether the CEO has IT knowledge

7. Whether the CEO encourages innovation

8. Experience in using IS

9. Failure experience with IS

10. Compatibility with existing IT/IS portfolio

(Required changes to existing systems/whether duplicate)

11. Probability of completion

12. Manpower (Morale/staff resource/Employee motivation/Staff turnover)

13. Skill of IT staff (Management/staff resource/ Competence of project leader)

14. Maturity of IT

15. Probability of benefit achievement

16. Hardware cost

17. Software cost

18. Implementation cost (Decreased productivity at first/disrupted work at first/Installation cost/Change management/loss of control)

19. Maintenance cost (Management time/the ability to perform maintenance faster/Ongoing expenses)

20. Consultant cost (Increased computer support needs/learning curve and training time)

21. Assist to achieve corporation goal (Support explicit business objectives)

22. Assist planning and control (Support implicit business objectives/data management)

23. Assist to make a management decision

24. Improve competitive advantage (improve customer satisfaction/reduced inventory/Improved growth and success)

25. Improve corporate image (leader in new technology/enhance the credibility and prestige of the organization/

Improved customer loyalty)

26. Reduce or avoid operation cost

27. Improve information quality
Jones and Beatty (1998), Irani (2002), Mirani and Lederer (1998), Iacovou et al. (1995)

Escobar-Perez (1998), Bacon (1992)

Escobar-Perez (1998), Bacon (1992), Mirani and Lederer (1998)

Escobar-Perez (1998), Bacon (1992), Ryan

and Harrison (2000)

Escobar-Perez (1998), Bacon (1992)

Authors proposed

Authors proposed

Authors proposed

Authors proposed

Jones and Beatty (1998)

Escobar-Perez (1998), Bacon (1992)

Ryan and Harrison (2000), Irani (2002), Mirani and Lederer (1998)

Irani (2002), Iacovou et al. (1995)

Authors proposed

Escobar-Perez (1998), Bacon (1992)

Jones and Beatty (1998), Iacovou et al. (1995),

O'Callaghan et al. (1992)

Jones and Beatty (1998), Mirani and Lederer

(1998), O’Callaghan et al. (1992)

Jones and Beatty (1998), Ryan and Harrison

(2000), Iacovou et al. (1995),

O'Callaghan et al. (1992)

Irani (2002), Mirani and Lederer (1998),

Iacovou et al. (1995), O'Callaghan et al. (1992),

Ryan and Harrison (2000)

Jones and Beatty (1998), Irani (2002),

Iacovou et al. (1995)

Escobar-Perez (1998), Bacon (1992),

Mirani and Lederer (1998)

Escobar-Perez (1998), Bacon (1992),

Irani (2002), Mirani and Lederer (1998),

Banerjee and Golhar (1994)

Escobar-Perez (1998), Bacon (1992),

Ryan and Harrison (2000), Irani (2002),

Mirani and Lederer (1998)

Jones and Beatty (1998), Irani (2002),

Mirani and Lederer (1998), Banerjee

and Golhar (1994), Iacovou et al. (1995)

Irani (2002), Orli and Tom, 1987,

Banerjee and Golhar (1994)

Jones and Beatty (1998), Irani (2002),

Mirani and Lederer (1998), Banerjee and

Golhar (1994), Iacovou et al. (1995),

O'Callaghan et al. (1992)

Jones and Beatty (1998), Iacovou et al. (1995) 
Table 1 (continued)

\begin{tabular}{ll}
\hline Criteria & Source \\
\hline $\begin{array}{l}\text { 28. Improve user satisfaction (Improved service/Job satisfaction/Work quality) } \\
\text { 29. System flexibility (Improved flexibility/ }\end{array}$ & $\begin{array}{l}\text { Jones and Beatty (1998), Kaplan (1986), } \\
\text { Ryan and Harrison (2000) } \\
\text { Improved response to changes) }\end{array}$ \\
$\begin{array}{ll}\text { Irani (2002), Mirani and Lederer (1998) } \\
\text { 30. Improve utilization of equipment (Productivity/ } \\
\text { Increased plant efficiency/Increased throughput) }\end{array}$ & Ryan and Harrison (2000), Irani (2002) \\
$\begin{array}{l}\text { 31. Improved cash flow } \\
\text { 32. Changed operating procedure (Business process } \\
\text { reengineering/organizational re-structure) }\end{array}$ & Jones and Beatty (1998), Iacovou et al. (1995) \\
$\begin{array}{ll}\text { 33. Improvement in communication } \\
\text { (Improved organizational teamwork) }\end{array}$ & $\begin{array}{l}\text { Premkumar and Ramamurthy (1995), } \\
\text { O'Callaghan et al. (1992) }\end{array}$ \\
$\begin{array}{l}\text { 34. Promotes concept of open culture } \\
\text { 35. Formalized procedures with accountability and responsibility } \\
\text { 36. Security protection (Provide greater data or software security) }\end{array}$ & $\begin{array}{l}\text { Mirani and Lederer (1998), } \\
\text { Banerjee and Golhar (1994); }\end{array}$ \\
\hline & $\begin{array}{l}\text { Irani (2002) } \\
\text { Irani (2002) }\end{array}$ \\
\hline
\end{tabular}

(1) AHP uses crisp values to score alternatives. The assessment of alternative projects requires the judgement of several experts. Every expert's feeling or perception about a score of 80 is not the same, so it is hard and unrealistic to let an expert express his/her own opinion in a crisp value. It would be easier for experts to give their opinions in linguistic variables such as high, medium, or low because a range value can express opinions and feelings more accurately.

(2) Mirani and Lederer (1998) suggested that the evaluation of IS effectiveness is subjective and relative by nature. Hence, it would be unrealistic to assign a crisp value to a subjective judgement, especially when the data is imprecise or fuzzy. Such data might be an estimating error, such as an underestimated cost or an indirect cost. Giving a range value to the judgement would be more appropriate.

(3) Some criteria in the decision-making process are qualitative, so there cannot be a crisp value for them.

(4) AHP only prioritizes the relative importance of all alternative projects and does not indicate the degree of difference or overlap between the projects in each criterion.

There are many uncertainties in the evaluation of IT investment before it is implemented, so it is difficult, and unwise, to give a crisp value to each criterion. Therefore, we introduce a fuzzy concept to use a range, or a relative degree to represent the value of each criterion in our model. The proposed fuzzy multi-criteria decision model (FMCDM), which uses linguistic variables and range values, not only overcomes the shortcomings of AHP, but also enables a decision-maker to determine where and how to improve the final project, and the benefits from it.

Furthermore, evaluation of a potential IT/IS project must also take the existing IT portfolio into account. This allows us to review the operation flow and information flow of an organization, avoid building redundant systems, and reduce waste as much as possible. It is very important to consider how to integrate the new system into the existing IT portfolio in order to maximize the benefits from the new IT portfolio.

\section{FMCDM based procedure for evaluating IT/IS investment}

The proposed FMCDM comprises a 2-stage evaluation process with a set of criteria for evaluating IT/IS investment. We briefly introduce the steps of FMCDM in Section 3.1. The selection of evaluation criteria is discussed in Section 3.2, followed by a description of the two evaluation teams and their functions in Section 3.3. 


\subsection{The steps of FMCDM}

We follow Prabhu and Vizayakumar's (2001) evaluation model and modify it for IT/IS evaluation. There are 10 steps in our proposed FMCDM approach. The steps are briefly introduced below and explained in detail in Appendix B.

Step 1: Form two evaluation teams: a weighting team and a scoring team, as described in Section 3.3.

Step 2: Determine the evaluation criteria. As explained in Section 3.2, given a set of criteria such as the one shown in Table 1, this step determines which criteria are to be used by the evaluation teams.

Step 3: Identify potential alternative projects and combine them with the existing IT portfolio to form the set of alternative candidates.

Step 4: Set proper linguistic scales (e.g., very high, high, medium, low, and very low) and ask the members of the weighting team to give their opinions on the relative importance of the evaluation criteria by pair-wise comparison.

Step 5: Convert the linguistic variables into triangle fuzzy numbers to get every member's fuzzy reciprocal matrix.

Step 6: Aggregate the weighting team members' fuzzy reciprocal matrices by geometric means and form the final aggregated fuzzy reciprocal matrix.

Step 7: Take the geometric row means of every criterion and normalize it to get its local weight. Then, calculate the global importance weight.

Step 8: Decide the rules for translating linguistic variables of score to a triangle fuzzy scale. As explained in Appendix B, evaluation criteria are divided into groups, and different translation formulas are applied according to the nature of the criteria.

Step 9: Aggregate all the scoring team members' opinions for each criterion and calculate the final score of all the alternative projects. Every alternative project has a score under each criterion. We multiply each score with the corresponding weight of the criterion and sum up the result to get the final score of the alternative.

Step 10: Translate each final triangle fuzzy score of the alternative projects into a crisp value for ranking purposes. There are many de-fuzzification formulas for translating fuzzy values to crisp values. We adopt Opricovic and Tzeng's (2003) formula for its proven superior performance.

\subsection{Selection of evaluation criteria}

The worksheet shown in Table 1 lists the criteria obtained from our review of IT/IS evaluation criteria in the literature. A Delphi approach was used to select which criteria would be used by the evaluation teams. Eight experts were chosen for this purpose. They helped prioritize the criteria and reached a consensus about the important criteria for IT/IS evaluation.

The experts were chosen according to their experience with IT/IS evaluation and formed a group with half of the IT providers and half of the IT customers. Table 2 shows the experts' personal profile and the hierarchy of the criteria they chose is shown in Fig. 1.

The experts decided that the organization's previous experience with IT/IS would not influence their evaluation of a new IT/IS project. They only remembered the lessons learned from any failures they may have had. They also agreed that the preferences or encouragement of the CEO were not important criteria in the evaluation process. The project would not be chosen simply to please the CEO. As a result, the total number of evaluation criteria was reduced to 26 from 36 listed in Table 1. 
Table 2

Experts' personal profile

\begin{tabular}{|c|c|c|c|c|c|c|c|c|c|}
\hline Number & Gender & Position & Department & Industry & Age & $\begin{array}{l}\text { Experience } \\
\text { (years) }\end{array}$ & $\begin{array}{l}\text { Academic } \\
\text { degree }\end{array}$ & IT skill & $\begin{array}{l}\text { IT/IS } \\
\text { experience }\end{array}$ \\
\hline 1 & Male & Manager & IT & $\begin{array}{l}\text { Public servant } \\
\text { in military }\end{array}$ & $>50$ & Over 20 & Master & Sophisticated & Much \\
\hline 2 & Female & Manager & IT & Bank & $>50$ & Over 20 & Bachelor & Normal & Much \\
\hline 3 & Male & Manager & IT & $\begin{array}{l}\text { Public servant } \\
\text { in military }\end{array}$ & $46-50$ & Over 20 & Bachelor & Sophisticated & Much \\
\hline 4 & Male & Manager & IT & Media & $40-45$ & Over 20 & Master & Sophisticated & Very much \\
\hline 5 & Male & Staff & Other & Telecommunication & $>50$ & Over 20 & Master & Normal & Much \\
\hline 6 & Male & Manager & Other & IT Provider & $40-45$ & $16-20$ & Master & Sophisticated & Much \\
\hline 7 & Male & Manager & IT & IT Provider & $46-50$ & $16-20$ & Master & $\begin{array}{l}\text { Very } \\
\text { Sophisticated }\end{array}$ & Very much \\
\hline 8 & Male & Manager & IT & IT Provider & $40-45$ & $16-20$ & Master & Sophisticated & Very much \\
\hline
\end{tabular}

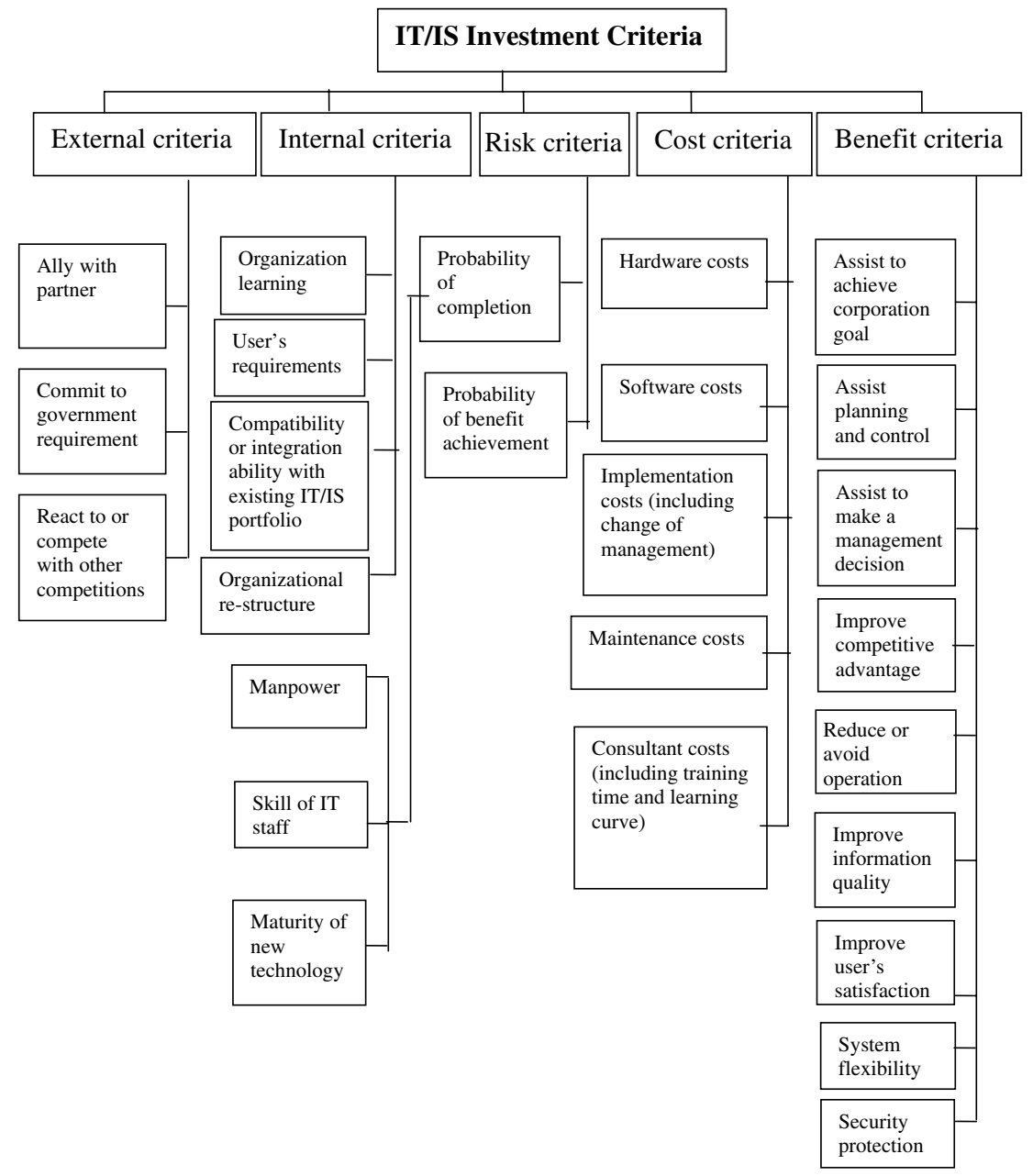

Fig. 1. Final consensus hierarchy of the criteria. 


\subsection{Evaluation teams}

Our proposed FMCDM approach calls for two teams, namely, a weighting team and a scoring team, instead of a single evaluation team used in other studies (King and Schrems, 1978; Metaxiotis et al., 1999). As mentioned earlier, the opinions of the stakeholders are important to the IT/IS evaluation process. The weighting team comprised different stakeholders, including an executive manager, the IT department manager, one or two IT staff, the accounting department manager, a couple of users whose departments or jobs would be affected by the new IT/IS, and the manager who proposed the new IT/IS project. Because user resistance is one of the main reasons for IT/IS project failures, we proposed the inclusion of more than one user in the team so users would know their opinions were valued and, they would share responsibility for making the project a success.

The mission of the weighting team is to give relative weights to all evaluation criteria. Team members only need to use linguistic variables to express their opinions, which is easier than giving an exact crisp number. The weighting result, representing the opinions of all stakeholders, can reflect the culture of organization, the characteristics of the IT/IS project, and its suitability for the company's requirements. Because different IT/IS users have their own special evaluation concerns, every new evaluation team may change the weighting of the criteria to reflect those concerns. This provides the organization with more flexibility.

The mission of the scoring team, on the other hand, is to evaluate alternatives to the existing IT/IS portfolio based on the criteria selected. The team consists of IT experts, accounting experts, an executive manager, an auditor and an outside consultant. The reasons for having so many different experts in the team are: (1) by including the executive manager we can ensure that the new project will not conflict with strategic business objectives; (2) including the IT experts ensures that the project is feasible with regard to its planning, design, methodology, technology, and architecture; (3) including the accounting experts ensures that the cost and benefit criteria are evaluated and that the project finally adopted will be financially feasible; (4) the auditors will understand the purpose of the project more precisely and assist with its subsequent implementation and monitor; and (5) external consultants can offer objective opinions.

Staff opinions may be different from those of managers because the staff may not be aware of the company's strategic goals. In this regard, the inclusion of the CEO in the scoring team plays a key role because he/she is supposed to fully understand the impact of all investment alternatives. Therefore, the clearer the decision process the better the final decision, as the CEO makes that decision.

Every member of the scoring team uses linguistic variables to score only those criteria he knows about according to his expertise. Through this exercise, the decision-maker can obtain a collective, unambiguous, and synthesized final suggestion easily. When the alternatives are evaluated, the new project is combined with the existing IT portfolio to gain the maximum benefit from the new investment.

\section{Case study: Selection of IT/IS investment using the FMCDM and IT portfolio approach for the Lion Travel Service Corporation of Taiwan}

To determine how the model could be used, we conducted a case study of the Lion Travel Service Corporation of Taiwan. The steps shown above were applied in the case study.

\subsection{Background of the Lion Travel Service Corporation}

The Lion Travel Service Corporation has the biggest share of the travel agency market in Taiwan. It has a staff of 600 , of which 30 are IT staff. The company is fully computerized and there are already many information systems in the working environment, including a web site with all kinds of information about personal and group travel where customers can make an order on-line. The current human resource 
management system only provides basic management functions. These are not sufficient and the human resource department staff must sometimes work overtime to provide reports that the manager requests. The company is considering whether, or not, to install a new human resource IS.

\subsection{Fuzzy MCDM for human resource IS evaluation}

We introduced our approach to the CEO of the Lion Travel Service Corporation who showed interest in our model and agreed to use it for evaluation. He asked one of the vice presidents to help us form the weighting and scoring teams. After a long interview with the vice president, we were sure that he understood what the model meant and we knew what the requirements of the new human resource IS were. Then, we identified the people who would be involved in the project and formed the two teams. There were eight persons in the weighting team: the vice president, who would make the final decision about the new system, one IT manager, one IT staff member, one accounting manager, one human resources manager and three users. There were seven experts in scoring team: one IT manager, one IT staff member, one accounting manager, one accounting staff member, the vice president, who would make the final decision about the new system, one auditor, and an external consultant. The personal profile of the members of the two teams is shown in Table 3.

The manager of the human resources department was nominated as the project leader. She told us that they had a number of choices: (i) develop a new IS by themselves, (ii) buy a new IS package, (iii) buy a package and customize it by themselves, (iv) buy a package and have it customized by the supplier, or (v) continue to use the existing IS. Eight human resource IS package providers submitted their proposals to her. None of them sold IS source codes, or provided customized service. Five of the proposals were rejected because their functions were obviously not suitable. Therefore, they were left with five alternatives to consider: (i) do not have a new IS, (ii) develop a new IS by themselves, (iii) buy a package from provider A, (iv) buy a package from provider B, or (v) buy a package from provider C.

Before evaluation, we held a meeting with all team members to make sure they knew what the model meant and how to evaluate it. Then, every member of the weighting team gave his/her opinions on the

Table 3

Personal profile of the two teams

\begin{tabular}{|c|c|c|c|c|c|c|c|c|}
\hline Number & Gender & Position & Department & Age & $\begin{array}{l}\text { Experience } \\
\text { (years) }\end{array}$ & Academic degree & IT skill & $\begin{array}{l}\text { IT/IS } \\
\text { experience }\end{array}$ \\
\hline \multicolumn{9}{|c|}{ The weighting team } \\
\hline 1 & Male & Vice President & & $40-45$ & $16-20$ & Master & Normal & Normal \\
\hline 2 & Female & Manager & Human Resource & $36-40$ & $16-20$ & Bachelor & Normal & Much \\
\hline 3 & Male & Manager & IT & $40-45$ & $16-20$ & Bachelor & Sophisticated & Very much \\
\hline 4 & Female & Manager & Accounting & $40-45$ & $16-20$ & Master & Normal & Much \\
\hline 5 & Male & Staff & IT & $30-35$ & $6-10$ & Master & Sophisticated & Very much \\
\hline 6 & Female & Staff & Human resource & $26-30$ & $6-10$ & Bachelor & Normal & Much \\
\hline 7 & Female & Staff & Human resource & $46-50$ & Over 20 & High school & Normal & Normal \\
\hline 8 & Male & Staff & Human resource & $40-45$ & $16-20$ & Bachelor & Normal & Much \\
\hline \multicolumn{9}{|c|}{ The scoring team } \\
\hline 1 & Male & Vice President & & $40-45$ & $16-20$ & Master & Normal & Normal \\
\hline 2 & Female & Manager & Accounting & $40-45$ & $16-20$ & Master & Normal & Much \\
\hline 3 & Male & Manager & IT & $40-45$ & $16-20$ & Bachelor & Sophisticated & Very much \\
\hline 4 & Female & Staff & Accounting & $30-35$ & $20-25$ & Bachelor & Normal & Much \\
\hline 5 & Male & Staff & IT & $30-35$ & $6-10$ & Master & Sophisticated & Very much \\
\hline 6 & Male & Staff & Auditor & $40-45$ & $16-20$ & Bachelor & Normal & Much \\
\hline 7 & Female & Consultant & & $30-35$ & $6-10$ & Master & Sophisticated & Very much \\
\hline
\end{tabular}


relative importance of the criteria. All the members' opinions were aggregated according to Steps 6 and 7 to obtain the geometric row mean values and importance weights of criteria. Those values of Level 1 criteria are shown in Table 4. The global weights of all criteria are shown in Table 5.

For each alternative project, experts on the scoring team gave a score to each criterion in which they had expertise. They also had to use a linguistic variable to score each alternative.

Seven of 26 criteria were cost criteria. They were 'Manpower', 'Hardware costs', 'Software costs', 'Implementation costs', 'Maintenance costs', 'Consultant costs', and 'Organizational re-structure'. We used the following formula (explained in Step 8) to translate linguistic variables into a normalized score between 0 and 100.

$$
r_{i j}=\frac{x_{j}^{-}-x_{i j}}{x_{j}^{-}-x_{j}^{*}} \times 100 .
$$

Table 4

Geometric row mean values and the importance weights of Level 1 criteria

\begin{tabular}{lll}
\hline & Geometric row mean values & Importance weights \\
\hline External criteria & $(0.30758,0.33434,0.37449)$ & $(0.04379,0.05391,0.06937)$ \\
Internal criteria & $(2.21914,2.58007,2.88831)$ & $(0.31592,0.41603,0.53499)$ \\
Risk criteria & $(0.72964,0.83392,0.95777)$ & $(0.10387,0.13447,0.17740)$ \\
Cost criteria & $(0.79595,0.88818,1.00591)$ & $(0.11331,0.14322,0.18632)$ \\
Benefit criteria & $(1.34653,1.56512,1.79781)$ & $(0.19170,0.25237,0.33300)$ \\
\hline
\end{tabular}

Table 5

Global weights of all criteria

\begin{tabular}{|c|c|}
\hline Criteria & Weight \\
\hline Ally with partner (improve trading partner relations) & $(0.01103,0.01710,0.02816)$ \\
\hline Commitment to government requirements & $(0.01168,0.01886,0.03130)$ \\
\hline React to or compete with competitors & $(0.01103,0.01796,0.03056)$ \\
\hline Organization learning & $(0.04538,0.08077,0.14186)$ \\
\hline Users' requirements & $(0.08148,0.15065,0.26686)$ \\
\hline Compatibility or integration ability with existing IT/IS portfolio & $(0.07285,0.13623,0.24652)$ \\
\hline Organizational re-structure & $(0.02718,0.04838,0.08969)$ \\
\hline Probability of completion & $(0.03969,0.05389,0.07502)$ \\
\hline Manpower & $(0.02549,0.04127,0.06690)$ \\
\hline Skill of IT staff & $(0.00551,0.00908,0.01631)$ \\
\hline Maturity of new technology & $(0.00222,0.00353,0.00641)$ \\
\hline Probability of benefit achievement & $(0.05905,0.08058,0.11161)$ \\
\hline Hardware costs & $(0.00659,0.01101,0.02008)$ \\
\hline Software costs & $(0.01255,0.02165,0.03903)$ \\
\hline Implementation costs & $(0.02526,0.04190,0.06975)$ \\
\hline Maintenance costs & $(0.02961,0.04842,0.08108)$ \\
\hline Consultants costs & $(0.01125,0.02023,0.03770)$ \\
\hline Assist to achieve corporation goal & $(0.01079,0.01932,0.03465)$ \\
\hline Assist planning and control & $(0.02138,0.03957,0.07191)$ \\
\hline Assist in making a management decision & $(0.02324,0.04177,0.07463)$ \\
\hline Improve competitive advantage & $(0.00999,0.01809,0.03334)$ \\
\hline Reduce or avoid operation costs & $(0.02201,0.04166,0.07767)$ \\
\hline Improve information quality & $(0.01594,0.02950,0.05554)$ \\
\hline Improve user satisfaction & $(0.01293,0.02485,0.04831)$ \\
\hline System flexibility & $(0.01151,0.02083,0.03797)$ \\
\hline Security protection & $(0.00889,0.01678,0.03307)$ \\
\hline
\end{tabular}


For other criteria we used the triangle fuzzy number conversion shown in Appendix B (Table 11) to translate linguistic variables to a score.

After translating all experts' linguistic variables to a score we averaged the score of all experts on each criterion for each alternative. Then, we multiplied each criterion by its corresponding global weight and summed up all values to get a final fuzzy score of each alternative. The results of the final fuzzy score of each criterion for all alternatives are shown in Table 6 and the final fuzzy net scores of all alternatives are shown in Table 7.

Finally, we used the formula discussed in Step 10 to get the crisp score value of all alternatives. The final crisp scores of all alternatives are shown in Table 8. Provider A is the recommended choice in this case study.

\subsection{Discussions}

How long does it take to carry out such an evaluation? From the formation of the two teams to the completion of the evaluation by both teams took only one day. The collected opinions were input to our model and the recommendation was known immediately, so our approach does not require much time.

Table 6

Final fussy score of each criterion for all alternatives

\begin{tabular}{|c|c|c|c|c|c|}
\hline & Don't invest & In-house dev. & Provider A & Provider B & Provider C \\
\hline Ally with partner & $(0.24,0.46,1.36)$ & $(0.24,0.46,1.36)$ & $(0,0,0.70)$ & $(0,0,0.70)$ & $(0,0,0.70)$ \\
\hline Government requirement & $(0.25,0.50,1.51)$ & $(0.25,0.50,1.51)$ & $(0.25,0.50,1.51)$ & $(0.25,0.50,1.51)$ & $(0.25,0.50,1.51)$ \\
\hline React competitions & $(0.15,0.36,1.27)$ & $(0.44,1.08,2.29)$ & $(0.70,1.44,2.75)$ & $(0.20,0.54,1.58)$ & $(0.20,0.54,1.58)$ \\
\hline Organization learning & $(0.78,2.01,7.05)$ & $(1.77,4.68,11.57)$ & $(4.19,8.69,16.36)$ & $(1.03,3.01,8.75)$ & $(1.29,4.01,10.44)$ \\
\hline Users'requirements & $(0.41,1.63,9.50)$ & $(4.35,10.32,20.80)$ & $(7.41,15.21,26.68)$ & $(2.87,7.60,18.54)$ & $(3.72,9.23,20.35)$ \\
\hline $\begin{array}{l}\text { Compatibility or ability to } \\
\text { integrate with } \\
\text { existing IT/IS portfolio }\end{array}$ & $(1.12,3.06,11.31)$ & $(5.90,13.25,24.87)$ & $(2.95,7.14,17.64)$ & $(2.25,6.12,15.83)$ & $(2.25,6.12,15.83)$ \\
\hline Organizational re-structure & $(0,0,0.68)$ & $(0,0,0.68)$ & $(0,0,0.68)$ & $(0,0,0.68)$ & $(0,0,0.68)$ \\
\hline Probability of completion & $(0.53,1.08,3.13)$ & $(2.18,3.95,6.25)$ & $(3.11,5.03,7.38)$ & $(0.70,1.62,3.88)$ & $(0.87,2.16,4.63)$ \\
\hline Manpower & $(2.15,3.72,6.60)$ & $(0,0,0)$ & $(0.95,2.06,4.82)$ & $(0.95,2.06,4.82)$ & $(0.95,2.06,4.82)$ \\
\hline Skill of IT staff & $(0.23,0.48,1.09)$ & $(0.25,0.58,1.25)$ & $(0.30,0.67,1.36)$ & $(0.27,0.61,1.33)$ & $(0.27,0.61,1.33)$ \\
\hline Maturity of IT & $(0.07,0.15,0.39)$ & $(0.10,0.224,0.49)$ & $(0.12,0.25,0.53)$ & $(0.12,0.26,0.53)$ & $(0.07,0.18,0.44)$ \\
\hline $\begin{array}{l}\text { Probability of } \\
\text { benefit achievement }\end{array}$ & $(1.28,2.15,5.39)$ & $(1.30,3.22,6.88)$ & $(4.23,6.98,10.79)$ & $(1.83,4.03,7.63)$ & $(1.83,4.03,7.63)$ \\
\hline Hardware costs & $(0.56,0$ & $(0$ & $(0.30$ & $(0.25,0$ & $1.45)$ \\
\hline Software costs & $(0.86,1.59,2.95)$ & $(0.15,0.43,1.13)$ & $(0.12,0.29,0.78)$ & $(0.03,0.14,0.35)$ & $(0.05,0.29,0.69)$ \\
\hline Implementation costs & $(1.73,3.07,5.27)$ & $(0.30,0.84,2.02)$ & $(0.74,1.82,4.25)$ & $(0.30,0.84,2.02)$ & $(0.35,1.12,2.64)$ \\
\hline Maintenance costs & $(2.26,3.87,7.03)$ & $(0.58,1.45,3.32)$ & $(0.87,2.10,4.94)$ & $(0.41,1.29,3.06)$ & $(0.87,2.10,4.94)$ \\
\hline Consultants costs & $(0.86,1.62,3.27)$ & $(0.95,1.82,3.72)$ & $(0.60,1.21,2.77)$ & $(0.49,0.94,2.01)$ & $(0.33,0.88,2.30)$ \\
\hline $\begin{array}{l}\text { Assist to achieve } \\
\text { corporation goal }\end{array}$ & $(0.23,0.50,1.58)$ & $(0.52,1.24,2.67)$ & $(0.84,1.74,3.21)$ & $(0.42,1.06,2.45)$ & $(0.42,1.06,2.45)$ \\
\hline Assist planning and control & $(0.49,1.08,3.44)$ & $(1.44,3.23,6.40)$ & $(1.63,3.49,6.88)$ & $(0.70,2.02,4.86)$ & $(0.89,2.28,5.33)$ \\
\hline $\begin{array}{l}\text { Assist in making a } \\
\text { management decision }\end{array}$ & $(0.54,1.16,3.70)$ & $(0.98,2.47,5.74)$ & $(1.79,3.78,7.39)$ & $(0.76,2.04,5.23)$ & $(0.76,2.04,5.23)$ \\
\hline Improve competitive advantage & $(0.22,0.48,1.58)$ & $(0.58,1.32,2.89)$ & $(0.73,1.56,3.16)$ & $(0.31,0.84,2.23)$ & $(0.31,0.84,2.23)$ \\
\hline Reduce or avoid operation costs & $(0.59,1.35,4.46)$ & $(1.48,3.55,7.69)$ & $(1.55,3.72,8.15)$ & $(1.07,2.87,6.92)$ & $(1.07,2.87,6.92)$ \\
\hline Improve information quality & $(0.37,0.84,2.89)$ & $(0.82,2.11,4.88)$ & $(1.22,2.74,5.78)$ & $(0.52,1.48,4.09)$ & $(0.81,2.00,4.88)$ \\
\hline Improve user satisfaction & $(0.30,0.68,2.35)$ & $(0.55,1.54,3.64)$ & $(0.99,2.22,4.69)$ & $(0.18,0.77,2.67)$ & $(0.30,1.02,2.99)$ \\
\hline System flexibility & $(0.29,0.64,2.06)$ & $(0.62,1.51,3.27)$ & $(0.85,1.91,3.84)$ & $(0.30,0.96,2.63)$ & $(0.42,1.19,2.92)$ \\
\hline Security protection & $(0,0,0.22)$ & $(0,0,0.22)$ & $(0,0,0.22)$ & $(0,0,0.22)$ & $(0,0,0.22)$ \\
\hline
\end{tabular}


Table 7

Final fuzzy net scores of all alternatives

\begin{tabular}{llllll}
\hline & Don't invest & In-house dev. & Provider A & Provider B & Provider C \\
\hline Sum & $(15.87,32.17,88.64)$ & $(23.52,55.92,120.30)$ & $(33.28,70.28,142.25)$ & $(14.86,39.47,101.22)$ & $(16.96,44.62$, \\
& & & & & $109.99)$ \\
\hline
\end{tabular}

Table 8

Crisp net scores of all alternatives

\begin{tabular}{llllll}
\hline & Don't invest & In-house dev. & Provider A & Provider B & Provider C \\
\hline Crisp value of sum & 45.56 & 66.58 & 81.94 & 51.85 & 57.19 \\
\hline
\end{tabular}

Taking a closer look at the evaluation results, we found that the opinions of the user department's staff and the user department's manager in the weighting team were: 'organization learning' was the most important criterion, 'users requirements' came second, and the third was 'probability of completion'. In contrast, the IT department's staff and the IT department's manager thought that the 'Compatibility or ability to integrate with the existing IT/IS portfolio' was the most important criterion, followed by 'Manpower', and the 'Probability of benefit achievement'. The results show that the users and IT staff have different priorities.

Our interview with the users revealed that they had had little chance to learn new knowledge about human resource management. If they had a new system, they could learn from it. For this reason, they valued 'Organization learning' the highest. The 'Users' requirements' criterion showed their dissatisfaction with the existing IS; they often needed to work overtime to compensate for the deficiencies of the existing system. Their strong desire for a new system was reflected by the weight they placed on 'Probability of completion'. Although human resources are important assets to the organization, there is high staff turnover. Users complained about poor training opportunities and unclear goals in career planning. If the new system incorporated functions to help staff with career planning and training, staff turnover rate might be lower and indirectly benefit the organization.

Members of the IT department valued 'Compatibility or the ability to integrate with the existing IT/IS portfolio' and 'Manpower' much more than users because they have a shortage of IT manpower. Most IT manpower is dedicated to developing core travel agency systems, due to the absence of travel IS providers. As the travel agency systems are the company's core business, these stakeholders paid more attention to them. But, since the human resource management system is a supportive system, they preferred to buy it from an IS provider. However, they were concerned about the effort needed to modify and maintain a purchased system.

Another reason that IT staff members paid more attention to "the compatibility or ability to integrate with the existing IT/IS portfolio was that they were aware of their responsibility for maintaining the new IT portfolio and ensuring there would be no duplicated systems in the new portfolio.

The overall evaluation results suggest that 'provider A', having the highest score, should be the recommended alternative. In fact, 'Provider A' is highly valued in many criteria, except for the 'Compatibility or ability to integrate with existing IT/IS portfolio' score, which is lower than the alternative 'in-house develop'; 'Hardware costs', 'Software costs', 'Implementation costs', and 'Maintenance costs' scores are lower than the alternative 'Don't invest in it'; the 'Consultants costs' score is lower than the alternative 'Don't invest in it' and 'in-house develop'. These results are understandable. It is unavoidable that 'Hardware', 'Software', 'Implementation' and 'Maintenance' costs are higher than 'not to invest'. But, we could ask Provider A to include a free-education service to lower the consultancy fee, if we decide to buy that alternative. We could also ask the engineers of Provider A to improve the data format layout or transference software to increase the 'Compatibility or the ability to integrate with the existing IT/IS portfolio'. 
From the evaluation results, we not only get a final recommendation, but also know how to improve the project we chose. Before translating the fuzzy scores to crisp scores to rank the alternatives, we know which criteria received better scores and their difference in degree from others in this final suggested project. Meanwhile, the criteria with lower scores can be compared to the scores for the same criteria in other alternatives to find some suggestions for improving the chosen project. We can tell the difference between them and decide our tolerance degree. We also can decide if there is room for improvement before negotiating with suppliers. If there is, we could get a better contract, as Smithson and Hirschheim (1998) emphasized. Therefore, the model is not only an evaluation tool, but also an analytical and negotiating tool.

The flexibility of our model allows evaluators to change the weights of the criteria to represent the specific characteristics of the IT/IS and reflect the culture of the organization. A new evaluation team can be formed to evaluate another new IS investment. Through the evaluation process, new criteria values can be obtained, which may be different from those of the previous project.

During the evaluation process, representatives of all stakeholders get a chance to present their opinions, so the model is also a discussion and communication tool for stakeholders.

\section{Conclusions}

In this study, we propose a method based on the fuzzy multi-criteria decision model for the evaluation of new IT/IS investments. We compare prior studies to compile a list of evaluation criteria. The final list of criteria is obtained using a Delphi approach. We form two evaluation teams, members of which include end-users, executive managers, and staff from the IT, accounting, and auditing departments. The evaluation model considers the existing IT portfolio to address possible duplicate investment and compatibility issues. Opinions are expressed with linguistic variables, instead of crisp values to reduce perceptive bias. Only a software worksheet, such as Excel, is required for calculation of the final results. The evaluation process is well documented and, therefore, traceable. This model provides the flexibility to change the weights of the criteria, and uses those weights to reflect special concerns about IT/IS, as well as organizational characteristics such as cultural, and contextual issues. It can also be used as an analytical tool to improve the project's contract to attain to the ideal goal. We believe the proposed approach is simple, cost-effective, and versatile and can be used as a decision support tool for any IT/IS investment evaluation.

\section{Acknowledgement}

This research has been partially supported by the MOE Program for Promoting Academic Excellence of Universities (91-H-FA08-1-4) of Taiwan.

\section{Appendix A}

Table 9.

\section{Appendix B}

The proposed FMCDM evaluation method is comprised of the following 10 steps.

Step 1: Form two evaluation teams: a weighting team and a scoring team. 
Table 9

Summary of criteria

\begin{tabular}{|c|c|}
\hline Author(s) & Criteria \\
\hline Bacon (1992), Escobar-Perez (1998) & $\begin{array}{l}\text { Net present value } \\
\text { Internal rate of return } \\
\text { Profitability index method } \\
\text { Average/accounting rate of return } \\
\text { Pay-back method } \\
\text { Budgetary constraints } \\
\text { Support explicit business objectives } \\
\text { Support implicit business objectives } \\
\text { Response to competitive systems } \\
\text { Support management decision making } \\
\text { Probability of achieving benefits } \\
\text { Legal/government requirements } \\
\text { Technical/system requirements } \\
\text { Introduce/learn new technology } \\
\text { Probability of project completion }\end{array}$ \\
\hline Jones and Beatty (1998) & $\begin{array}{l}\text { Reduced transaction costs } \\
\text { Improved cash flow } \\
\text { Reduced inventory } \\
\text { Improved information flow } \\
\text { Improved internal operations } \\
\text { Improved service } \\
\text { Improved trading partner relations } \\
\text { Improved competitive advantage } \\
\text { Disrupted work at first } \\
\text { Changed operating procedures } \\
\text { Decreased productivity at first } \\
\text { Long learning time } \\
\text { Required new hardware/software } \\
\text { Increased computer support needs } \\
\text { Substantial site preparation } \\
\text { Required changes to existing systems }\end{array}$ \\
\hline Irani (2002) & $\begin{array}{l}\text { Improved growth and success } \\
\text { Leader in new technology } \\
\text { Improved market share } \\
\text { Market leadership } \\
\text { Enhanced competitive advantage } \\
\text { Improved flexibility } \\
\text { Improved response to changes } \\
\text { Improved product quality } \\
\text { Improved organizational teamwork } \\
\text { Promotes concept of open culture. } \\
\text { Improved integration with other business functions } \\
\text { Increased productivity } \\
\text { Increased plant efficiency } \\
\text { Reduced delivery lead-times } \\
\text { Reduced manufacturing lead-times } \\
\text { Improved capacity planning } \\
\text { Improved stability of MPS } \\
\text { Improved data management } \\
\text { Improved manufacturing control } \\
\text { Improved accuracy of decisions }\end{array}$ \\
\hline
\end{tabular}


Table 9 (continued)

\begin{tabular}{|c|c|}
\hline Author(s) & Criteria \\
\hline & $\begin{array}{l}\text { Reduced raw material inventory } \\
\text { Reduced levels of WIP } \\
\text { Reduced labor costs } \\
\text { Reduced manufacturing costs } \\
\text { Increased throughput } \\
\text { Improved data availability } \\
\text { and reporting structure } \\
\text { Improved communication through 'on-line' order progressing } \\
\text { Improved product tractability } \\
\text { Formalized procedures with accountability and responsibility } \\
\text { Improved schedule adherence } \\
\text { Cost of ownership: system support } \\
\text { Management/staff resources } \\
\text { Management time } \\
\text { Management effort and dedication } \\
\text { Employee time } \\
\text { Employee training } \\
\text { Employee motivation } \\
\text { Changes in salaries } \\
\text { Staff turnover } \\
\text { Productivity losses and organizational impact } \\
\text { Strain on resources } \\
\text { Business process re-engineering } \\
\text { Security software protection } \\
\text { Security breaches } \\
\text { Organizational re-structuring }\end{array}$ \\
\hline $\begin{array}{l}\text { Ryan and } \\
\text { Harrison (2000) }\end{array}$ & $\begin{array}{l}\text { Productivity } \\
\text { Training } \\
\text { Labor savings } \\
\text { Work quality } \\
\text { Change of management } \\
\text { Learning curve } \\
\text { Job satisfaction } \\
\text { Better decisions } \\
\text { Improvement in communications } \\
\text { Morale } \\
\text { Loss of control }\end{array}$ \\
\hline $\begin{array}{l}\text { Mirani and } \\
\quad \text { Lederer (1998) }\end{array}$ & $\begin{array}{l}\text { Enhances competitiveness or create strategic advantage } \\
\text { Enables the organization to catch up with competitors } \\
\text { Aligns with stated organizational goals } \\
\text { Helps establish useful linkages with other organizations } \\
\text { Enables the organization to respond more quickly to change } \\
\text { Improves customer relations } \\
\text { Provides new products or services to customers } \\
\text { Provides better products or services to customers } \\
\text { Enables faster retrieval or delivery of information or reports } \\
\text { Enables easier access to information } \\
\text { Improves management information for strategic planning } \\
\text { Improves the accuracy or reliability of information } \\
\text { Improves information for operational control } \\
\text { Presents information in a more concise manner or better format }\end{array}$ \\
\hline
\end{tabular}


Table 9 (continued)

Author(s)

Mcaulay et al. (2002)

\section{Criteria}

Increases the flexibility of information requests Saves money by reducing travel costs

Saves money by reducing communication costs Saves money by reducing system modification or enhancement costs

Allows other applications to be developed faster Allows previously infeasible applications to be implemented Provides the ability to perform maintenance faster Saves money by avoiding the need to increase the work force Speeds up transactions or shorten product cycles Increase return on financial assets

Enhances employee productivity or business efficiency

Enhances competitive/strategic advantage

Increases access to expertise

Increases flexibility

Reduces uncertainty

Eliminates unnecessary functions

Improves management information for strategic business planning Improves information for management decision making

Enables faster retrieval or delivery of information for reports Improves reliability or accuracy of information

Enables focus on core in-house operations

Improves the quality of IT systems

Improves service quality/service delivery to customers

Provide new and/or broader ranges of products/services

Improves disaster recovery

Increases process efficiency

Reduces technology costs through reduced system

enhancements and modifications

Reduces operations costs

Reduces workforce costs

Increases access to new technologies

Allows previously unfeasible applications to be implemented

Allows faster development of applications

Reduces the risk of technological obsolescence

Vendor opportunism

Lack of flexibility (becoming locked into the vendor)

Potential loss of secrets and intellectual property

Change in commitment or financial stability of a supplier

Client engaged in new line of business-requires

changes to contract or even termination of contract

Lack of active management of the vendor by the client

Over-dependence on the vendor

Vendor's lack of client's enterprise knowledge

Treating IT as an undifferentiated commodity to be outsourced

Lack of employee morale leading to poor performance and

high staff turnover

Loss of expertise within the company

Vendor fails to provide contracted service to the required level

Costs of controlling the vendor very high 
Step 2: Pick appropriate evaluation criteria and organized them in an appropriate format.

Step 3: Identify various potential alternative projects and combine them with the existing IT portfolio to form the set of alternative candidates.

Step 4: Set proper linguistic scales (very high, high, medium, low, and very low) and ask the members of the weighting team to give their opinions by pair-wise comparison of evaluation criteria.

Step 5: Convert the linguistic variables into triangle fuzzy numbers as shown in Table 1 . This gives everyone's fuzzy reciprocal matrix (Table 10).

Step 6: Aggregate the weighting team members' fuzzy reciprocal matrices by geometric means and form the final aggregated fuzzy reciprocal matrix. In the same way, aggregate the scoring team members' opinions by geometric means.

Step 7: Take the geometric row means of every criterion and normalize it to get its local weight. Then, calculate the global importance weight.Let $\widetilde{A}=\left[\tilde{a}_{u v}\right]_{k^{*} k}$ be the fuzzy reciprocal matrix; $k$, the number of criteria; and $a_{u v}$, the relative importance of $u$ criteria over $v$ criteria.

$\tilde{r}_{u}=\left(\tilde{a}_{u 1} \otimes \tilde{a}_{u 2} \otimes \tilde{a}_{u 3} \otimes \cdots \otimes \tilde{a}_{u k}\right)^{1 / k}$,

where $k$ is number of criteria; the symbol $\otimes$ denotes fuzzy multiplication; and $\tilde{r}_{u}$ is the geometric row mean of relative importance of the $u$ th criterion over all the other criteria.

$\tilde{w}_{u}=\tilde{r}_{u} \otimes\left(\tilde{r}_{1} \oplus \tilde{r}_{2} \oplus \cdots \oplus \tilde{r}_{k}\right)^{-1}$,

where the symbol $\oplus$ denotes fuzzy addition, and $\tilde{w}_{u}$ is the normalized local weight of the $u$ th criterion.

Normalize the geometric row mean of $\tilde{r}_{u}$ get the normalized local weight of every criterion. The local weight of every criterion is then multiplied by its higher level's weight to get the global weight. For example, in Fig. 1, the local weight of 'Manpower' is $(0.64,0.77,0.89)$, the local weight of 'Probability of completion' is $(0.38,0.40,0.42)$, the local weight of 'Risk criteria' is $(0.10,0.13,0.18)$, so the global weight of 'Manpower' is

$$
\begin{aligned}
& (0.64,0.77,0.89) \otimes(0.38,0.40,0.42) \otimes(0.10,0.13,0.18) \\
& \quad=(0.64 * 0.38 * 0.10,0.77 * 0.40 * 0.13,0.89 * 0.42 * 0.18)=(0.03,0.04,0.07) .
\end{aligned}
$$

Step 8: Decide the rules for scoring. All criteria are separated into two groups, the cost criteria group and the benefit (or non-cost) criteria group, using different translation formulas.

The scoring formula for the benefit criteria translates linguistic variables into triangle fuzzy numbers directly, as shown in Table 2. Logically, a higher linguistic value means a larger value

Table 10

Linguistic scale and its triangle fuzzy number conversion

\begin{tabular}{ll}
\hline Linguistic scale & Triangle fuzzy scale \\
\hline Very high $(9: 1)$ & $(8,9,9)$ \\
Between very high and high $(7: 1)$ & $(6,7,8)$ \\
High $(5: 1)$ & $(4,5,6)$ \\
Between high and medium $(3: 1)$ & $(2,3,4)$ \\
Medium (2:1) & $(1 / 2,1,2)$ \\
Exactly equal (1:1) & $(1,1,1)$ \\
between medium and low (1:3) & $(1 / 4,1 / 3,1 / 2)$ \\
Low (1:5) & $(1 / 6,1 / 5,1 / 4)$ \\
Between low and very low (1:7) & $(1 / 8,1 / 7,1 / 6)$ \\
Very low (1:9) & $(1 / 9,1 / 9,1 / 8)$ \\
\hline
\end{tabular}


Table 11

Linguistic scale and its triangle fuzzy number conversion

\begin{tabular}{ll}
\hline Linguistic scale & Triangle fuzzy scale \\
\hline Very high (1) & $(85,100,100)$ \\
High (2) & $(65,80,95)$ \\
Medium (3) & $(40,60,75)$ \\
Low (4) & $(13,30,55)$ \\
Very low (5) & $(0,0,25)$ \\
\hline
\end{tabular}

of triangle fuzzy numbers, which translates into a better score, indicating that the alternative project will be more beneficial to the company (Table 11).

With regard to the cost criteria, since the highest linguistic value of cost criteria means the worst score, the translation uses the following normalization formula to turn a higher $x_{i j}$ linguistic value into a lower $r_{i j}$ score:

$r_{i j}=\frac{x_{j}^{-}-x_{i j}}{x_{j}^{-}-x_{j}^{*}} \times 100$,

where $i$ is the $i$ th alternative project; $j$ is the $j$ th criteria; $x_{i j}$ is the score of the $i$ th alternative under the $j$ th criteria; $r_{i j}$ is the normalized score of $x_{i j} ; x_{j}^{*}$ is the lowest score, which means the lowest cost, under the $j$ th criteria; and $x_{j}^{-}$, is the highest score under the $j$ th criteria. The range of triangle fuzzy values is between 0 and 100 , so we multiply the normalization value $r_{i j}$ by 100 .

Step 9: Aggregate all the experts' opinions for each criterion and calculate the final score of all the alternative projects. Every alternative project has a score for each criterion. We multiply each score with the corresponding weight of the criterion and sum up the result to get the final net score of the alternative. The calculation is as follows:

Let $\tilde{w}_{j}=\left(l_{j}, w_{j}, u_{j}\right)$ be the global weight of the $j$ th criterion; $l_{i}$, the lowest range value; $w_{i}$, a median; and $u_{i}$, the largest range value.

Also, let $\tilde{r}_{i j}=\left(L E_{i j}, M E_{i j}, U E_{i j}\right)$ be the score of the $i$ th alternative under the $j$ th criterion; $L E_{i j}$, the lowest range value; $M E_{i j}$, a median and $U E_{i j}$, the largest range value.

Then, the $j$ th criterion score of $i$ th alternative is

$\widetilde{R}_{i j}=\left(L_{i j}, M_{i j}, U_{i j}\right)=\tilde{r}_{i j} \otimes \tilde{w}_{j}=\left(L E_{i j} * l_{j}, M E_{i j} * m_{j}, U E_{i j} * u_{j}\right)$.

Sum up every score of all criteria for the $i$ th alternative and we get the final score:

$\widetilde{R}_{i}=\left(L_{i}, M_{i}, U_{i}\right)=\sum_{j=1}^{k} \tilde{r}_{i j} \otimes \tilde{w}_{j}=\left(\sum_{j=1}^{k} L E_{i j} * l_{j}, \sum_{j=1}^{k} M E_{i j} * m_{j}, \sum_{j=1}^{k} U E_{i j} * u_{j}\right)$.

Step 10: Translate each final triangle fuzzy score of the alternative projects into a crisp value for ranking purposes.

We use Opricovic and Tzeng's (2003) de-fuzzification formula to prioritize the ranks as follows: $R_{i}=L_{i}+\left\{\left(M_{i}-L_{i}\right)+\left(U_{i}-L_{i}\right)\right\} / 3$,

where $R_{i}$ is the crisp final score of the $i$ th alternative project; $L_{i}$ is the lowest range value; $M_{i}$ is a median; and $U_{i}$ is the largest range value.

The higher the value of $R$, the greater the benefit an alternative project would be to the company. Therefore, the project with the highest $R$ value would be the right choice for investment. 


\section{References}

Bacon, C.J., 1992. The use of decision criteria in selecting information systems/technology investments. MIS Quarterly 16 (3), $335-353$.

Ballantine, J., Levy, M., Powell, P., 1998. Evaluating information systems in small and medium-sized enterprises: Issues and evidence. European Journal of Information Systems 7 (4), 241-251.

Banerjee, S., Golhar, D.Y., 1994. Electronic data interchange: Characteristics of users and nonusers. Information and Management 26, 65-74.

Boland, R.J., Hirschheim, R.A., 1987. Critical Issues in Information Systems Research. John Wiley \& Sons, Chichester.

Earl, M.J., 1989. Management Strategies for Information Technology. Prentice Hall, Hemel Hempstead, UK.

Escobar-Perez, B., 1998. Information systems investment decisions in business practice: The Spanish case. European Journal of Information Systems 7 (3), 202-209.

Farbey, B., Land, F., Targett, D., 1993. IT Investment: A Study of Methods and Practices, Management Today. ButterworthHeinemann Ltd., UK.

Hochstrasser, B., Griffiths, C., 1991. Controlling Information Technology Investments: Strategy and Management. Chapman and Hall, London.

Iacovou, C.L., Benbasat, I., Dexter, A.S., 1995. Electronic data interchange and small organizations: Adoption and impact of technology. MIS Quarterly 19 (4), 465-485.

Irani, Z., 2002. Information systems evaluation: Navigating through the problem domain. Information and Management 40 (1), 11-24.

Irani, Z., Love, P.E.D., 2002. Developing a frame of reference for ex-ante IT/IS investment evaluation. European Journal of Information Systems 11 (1), 74-82.

Irani, Z., Ezingeard, J.-N., Grieve, R.J., 1998. Costing the true costs of IT/IS investments: A focus during management decision making. The Journal of Logistics Information Management 11 (1), 38-43.

Jones, M.C., Beatty, R.C., 1998. Towards the development of measures of perceived benefits and compatibility of EDI: A comparative assessment of competing first order factor models. European Journal of Information Systems 7 (3), 210-220.

Kaplan, R.S., 1986. Must CIM be justified by faith alone? Harvard Business Review 64 (2), 87-95.

King, J.L., Schrems, E.L., 1978. Cost-benefit analysis in information systems development and operation. Computing Surveys 10 (1), $19-34$.

Lefley, F., Sarkis, J., 1997. Short-termism and the appraisal of AMT capital projects in the US and UK. International Journal of Production Research 35 (2), 341-368.

Mcaulay, L., Doherty, N., Keval, N., 2002. The stakeholder dimension in information systems evaluation. Journal of Information Technology 17 (4), 241-255.

Metaxiotis, K.S., Papakonstantinou, A.P., Psarras, J.E., 1999. Evaluating the integrated measurement and evaluation system IMES: A success story. Communications of the Association for Information Systems 2. Available from: http://cais.isworld.org/articles/ default.asp?vol=2\&art $=15$. Article 15 .

Mirani, R., Lederer, A.L., 1998. An instrument for assessing the organizational benefits of IS projects. Decision Sciences 29 (4), $803-$ 838.

O'Callaghan, R., Kaufmann, P.J., Konsynski, B.R., 1992. Adoption correlates and share effects of electronic data interchange systems in marketing channels. Journal of Marketing 56, 45-56.

Opricovic, S., Tzeng, G.H., 2003. Defuzzificaion for a fuzzy multi-criteria decision model. International Journal of Uncertainty, Fuzziness and Knowledge-based Systems 11 (5), 635-652.

Orli, R.J., Tom, J.C., 1987. If it's worth more than it costs, buy it! Journal of Information Systems Management 4 (3), 85-89.

Orlikowski, W., 1992. The duality of technology: Rethinking the concept of technology in organizations. Organization Science 3 (3), 398-427.

Powell, P., 1992. Information technology evaluation: Is it different? The Journal of the Operational Research Society 43 (1), $29-42$.

Prabhu, T.R., Vizayakumar, K., 2001. Technology choice using FHDM a case of iron-making technology. IEEE Transactions on Engineering Management 48 (2), 209-222.

Premkumar, G., Ramamurthy, K., 1995. The role of interorganizational and organizational factors on the decision mode for adoption of interorganizational systems. Decision Sciences 26 (3), 303-336.

Renkema, T.J.W., 2000. The IT Value Quest: How to Capture the Business Value of IT-Based Infrastructure. John Wiley \& Sons, Chapter 6.

Renkema, T.J.W., Berghout, E.W., 1997. Methodologies for information systems investment evaluation at the proposal stage: A comparative review. Information and Software Technology 39 (1), 1-13.

Ryan, S.D., Harrison, D.A., 2000. Considering social subsystem costs and benefits in information technology investment decisions: A view from the field on anticipated payoffs. Journal of Management Information Systems 16 (4), 11-40.

Saaty, T.L., 1980. The Analytic Hierarchy Process. McGraw-Hill Inc.

Serafeimidis, V., Smithson, S., 2000. Information systems evaluation in practice: A case study of organizational change. Journal of Information Technology 15 (2), 93-105. 
Serafeimidis, V., Smithson, S., 2003. Information systems evaluation as an organizational institution-Experience from a case study. Information Systems Journal 13 (3), 251-274.

Smithson, S., Hirschheim, R., 1998. Analyzing information systems evaluation: Another look at an old problem. European Journal of Information Systems 7 (3), 158-174.

Stouffer, D., Rachlin, S., 2002. A Summary of First Practices and Lessons Learned in Information Technology Portfolio Management. Federal CIO Council Best Practices Committee.

Strassmann, P., 1997. The Squandered Computer. The Information Economics Press, New Canaan.

Vaid-Raizada, V.K., 1983. Incorporation of intangibles in computer selection decisions. Journal of Systems Management 33 (11), 30 36.

Voss, C.A., 1986. Managing advanced manufacturing technology. International Journal of Operations and Production Management $6(5), 4-7$.

Walsham, G., 1993. Interpreting Information Systems in Organizations. John Wiley \& Sons, Chichester.

Willcocks, L., 1992. Evaluating information technology investments: Research findings and reappraisal. Journal of Information Systems 2 (4), 243-268.

Willcocks, L., Lester, S., 1997. Assessing IT productivity: Any way out of The Labyrinth? In: Willcocks, L., Feeny, D., Islei, G. (Eds.), Managing IT As A Strategic Resource. McGraw-Hill, Maidenhead, pp. 64-89. 